\title{
EFFECT OF OPTIMIZATION OF TWEEN 80 AND PROPYLENE GLYCOL AS A SURFACTANT AND COSURFACTANT ON THE PHYSICAL PROPERTIES OF ASPIRIN MICROEMULSION
}

\author{
KORI YATI*, YUDI SRIFIANA, FARENSYAH PUTRA
}

Department of Pharmacy, Faculty of Pharmacy and Science, University of Muhammadiyah, Jakarta, Indonesia. Email: koriyati@ymail.com Received: 21 April 2017, Revised and Accepted: 13 July 2017

ABSTRACT

Background: Aspirin is recommended as a first-line antiplatelet drug for all types of acute diseases that cause thrombosis in the blood vessel, especially in cardiovascular disease. Orally administered aspirin has side effects such as the risk of gastrointestinal bleeding and has presystemic metabolism in the gastrointestinal tract and liver. Transdermal delivery offers an alternative for administering aspirin that by passes the gut and this may be more convenient and safe for long-term use. This study used a form of microemulsion to prevent hydrolysis of aspirin because it contains a high concentration of the surfactant. A microemulsion is a dosage form that can penetrate into the skin for transdermal delivery.

Objectives: The aim of this research was to evaluate the effect of Tween 80 and propylene glycol as the surfactant and cosurfactant on the physical stability of the microemulsion.

Materials and Methods: Various concentrations of Tween 80 and propylene glycol (2:1) were used 54\%, 57\%, 60\%, and 63\%, and the physical stability of the different microemulsions was tested for 6 weeks.

Result: The results showed that the formula F3 was the most stable formula. The formula F3 showed the following properties such as pH of $3.74 \pm 0.30$, viscosity of $1198.76 \pm 56.02 \mathrm{cps}$, BJ of $1.0669 \pm 0.005 \mathrm{~g} / \mathrm{mL}$, surface tension of $38.77 \pm 0.43 \mathrm{dyne} / \mathrm{cm}$, and particle size of $49.46 \pm 6.91 \mathrm{~nm}$.

Conclusions: Based on the results concluded that the optimum concentration of Tween 80 as the surfactant and propylene glycol as the cosurfactant with a ratio of $2: 1$ was $60 \%$

Keywords: Aspirin, Transdermal, Microemulsions, Tween 80.

(C) 2017 The Authors. Published by Innovare Academic Sciences Pvt Ltd. This is an open access article under the CC BY license (http://creativecommons org/licenses/by/4. 0/) DOI: http://dx.doi.org/10.22159/ijap.2017.v9s1.71_78

\section{INTRODUCTION}

Aspirin is a nonsteroidal anti-inflammatory drug that is efficient as an antiplatelet because it can inhibit the activity of the enzyme cyclooxygenase in platelets. Orally administered aspirin has side effects such as the risk of gastrointestinal bleeding and has presystemic metabolism in the gastrointestinal tract and liver. This situation is exacerbated by the continued use of aspirin that can causes serious side effects in the gastrointestinal tract. In view of the poor effectiveness of oral administration, a transdermal drug delivery system is an alternative method that can improve the effectiveness of aspirin use $[1,2]$. Transdermal delivery by passes the gut and may, therefore, be more convenient and safe for long-term use. A microemulsion is a dosage form used for penetration in transdermal delivery. It contains a surfactant, so it is fine when formulated with aspirin because aspirin is a drug that can be hydrolyzed in the presence of water. The presence of a surfactant can prevent hydrolysis of aspirin by protecting it in micelles that can obstruct the entry of hydroxyl groups that attack the ester groups [3].

The surfactants used in this study were Tween 80. Surfactants help in forming oil-in-water microemulsions with a cosurfactant, which improves the solubilization. Short to medium chain length alcohols (C3-C8) are commonly added as cosurfactants, which further reduce the interfacial tension and fluidity of the interface. This study used propylene glycol as the cosurfactant. The aim of this study was to investigate the effect of Tween 80 and propylene glycol as a surfactant and cosurfactant on the physical properties of aspirin microemulsions.

\section{MATERIALS AND METHODS}

Materials

Aspirin was purchased from of Yixing City, Xingyu. Virgin coconut oil was purchased from LIPI Cibinong, Bogor. Tween 80 was purchased from PT. KAO Chemical. Propylene glycol was purchased from PT. Dow Chemical Pacific. Methylparaben and Propylparaben were purchased from PT. Clariant

\section{Pseudoternary phase diagram construction}

For preparing the microemulsion first, preliminary experiments were first carried out using pseudoternary phase diagrams. In the preliminary experiments, the microemulsion formula was optimized with virgin coconut oil as the oil phase, a combination of Tween 80 and propylene glycol $(2: 1)$ as the surfactant and cosurfactant, and distilled water as the aqueous phase.

\section{Preparation of aspirin microemulsions}

Various microemulsions were chosen from the pseudoternary phase diagrams. The concentration of virgin coconut oil was $5 \%$, and combination $(54 \%, 57 \%, 60 \%$, and $63 \%)$ of Tween 80 , and propylene glycol (2:1) concentrations were used. Aspirin was dispersed in the virgin coconut oil as the oil phase and then added to a mixture of distilled water and Tween 80. Then, propylene glycol was added to form a clear and homogeneous mixture (Table 1).

\section{Organoleptic}

Organoleptic includes observation of the shape, clarity, and smell. Observations were carried out for 6 weeks, on weeks 0,3 , and 6 . 
Determination of $\mathbf{p H}$

$\mathrm{pH}$ measurement was performed using a $\mathrm{pH}$ meter, and observations were carried out for 6 weeks, on weeks 0,3 , and 6, at room temperature [4].

\section{Density measurement}

Density was measured using a pycnometer. Observations were carried out for 6 weeks, on weeks 0,3 , and 63 .

\section{Viscosity measurement}

Measurements were carried out using a Brookfield viscometer LVDV-E with spindle number 3 at a speed of $30 \mathrm{rpm}$ for 6 weeks, on weeks 0 , 3 , and 6.

\section{Particle size measurements}

The particle size was measured using a nanoparticle size analyzer. The solution was placed in a cuvette that was inserted into the sample holder.

\section{Surface tension measurement}

This measurement was carried out for 6 weeks, every week to 0,3 , and 6 at room temperature. The surface tension was measured using a tensiometer with Du Noüy method [5].

\section{Phase separation}

The aspirin microemulsions were centrifuged at $3750 \mathrm{rpm}$ for $5 \mathrm{hrs}$ at room temperature, and then, the phase changes were observed. The aspirin microemulsions were also subjected to a freeze-thaw test at $4^{\circ} \mathrm{C}$ and $45^{\circ} \mathrm{C}$ to observe the phase separation that occurs.

\section{Data analysis}

The data were statistically tested included with two-way analysis of variance (ANOVA) with a $95 \%$ confidence level, to determine significant differences between the formula test results.

\section{RESULTS AND DISCUSSION}

\section{Preparation of aspirin microemulsions}

The results showed that the formula produces a clear microemulsion is virgin coconut oil ( $5 \%$ ) as the oil phase, a combination of Tween 80 and propylene glycol as the surfactant and cosurfactant $(2: 1)(54 \%, 57 \%$, $60 \%$, and $63 \%$ ), and distilled water up to $100 \%$. The microemulsion could be held steady during the observation time of 1 week.

\section{Organoleptic}

Based on organoleptic observations for 6 weeks, only the F1 formula was physically opaque since the $1^{\text {st }}$ week. In contrast, the formulas F2, F3, and F4 showed no change, indicating that these three formulas have good stability during storage (Table 2).

\section{Density measurement}

The 6 weeks observations revealed that a higher surfactant concentration leads to a higher density (Fig. 1). Further, with a higher surfactant concentration, the solubilization process will increase owing to the increase in the micellar concentration [3]. This makes the microemulsions clear, with smaller particles, so that the density increases.

\section{Determination of $\mathbf{p H}$}

Results of $\mathrm{pH}$ measurement for 6 weeks showed a decrease in $\mathrm{pH}$ during storage (Fig. 2). A higher surfactant concentration led to higher $\mathrm{pH}$ of the microemulsions. This probably because the formation of micelles with higher surfactant concentration also increased, and thus, more of the aspirin can be protected in the micelles and hydrolysis can be decreased. In contrast, for F1 and F2 with a smaller concentration of surfactant, much of the aspirin was hydrolyzed to salicylic acid and acetic acid, thus decreasing the $\mathrm{pH}$ of the microemulsions.

\section{Surface tension measurement}

The measurement results showed that with increasing surfactant and cosurfactant concentrations, the surface tension is lower (Fig. 3). Theoretically, increases in the surfactant concentration will cause a
Table 1: Formula of aspirin microemulsions

\begin{tabular}{llllll}
\hline \multirow{2}{*}{ Materials } & \multicolumn{3}{l}{ Formula (\%) } & \multirow{2}{*}{ Function } \\
\cline { 2 - 5 } & F1 & F2 & F3 & F4 & \\
\hline Aspirin & 3 & 3 & 3 & 3 & API \\
Virgin coconut oil & 5 & 5 & 5 & 5 & Oil phase \\
Tween 80 & 36 & 38 & 40 & 42 & Surfactant \\
Propylene glycol & 18 & 19 & 20 & 21 & Cosurfactant \\
Nipagin & 0.18 & 0.18 & 0.18 & 0.18 & Preservative \\
Nipasol & 0.02 & 0.02 & 0.02 & 0.02 & Preservative \\
Distilled water ad & 100 & 100 & 100 & 100 & Water phase \\
\hline
\end{tabular}

API: Active pharmaceutical ingredient

Table 2: Organoleptic observations of aspirin microemulsions

\begin{tabular}{lllll}
\hline Formula & Organoleptic & \multicolumn{2}{l}{ Time (week) } & \\
\cline { 3 - 5 } & & $\mathbf{0}$ & $\mathbf{3}$ & $\mathbf{6}$ \\
\hline F1 & smell & $\mathrm{sp}$ & $\mathrm{sp}$ & $\mathrm{sp}$ \\
& clarity & $\mathrm{O}$ & $\mathrm{o}$ & $\mathrm{o}$ \\
& shape & $\mathrm{flu}$ & $\mathrm{flu}$ & $\mathrm{flu}$ \\
F2 & smell & $\mathrm{sp}$ & $\mathrm{sp}$ & $\mathrm{sp}$ \\
& clarity & $\mathrm{c}$ & $\mathrm{c}$ & $\mathrm{c}$ \\
& shape & $\mathrm{flu}$ & $\mathrm{flu}$ & $\mathrm{flu}$ \\
& smell & $\mathrm{sp}$ & $\mathrm{sp}$ & $\mathrm{sp}$ \\
& clarity & $\mathrm{c}$ & $\mathrm{c}$ & $\mathrm{c}$ \\
& shape & $\mathrm{flu}$ & $\mathrm{flu}$ & $\mathrm{flu}$ \\
F4 & smell & $\mathrm{Sp}$ & $\mathrm{sp}$ & $\mathrm{sp}$ \\
& clarity & $\mathrm{c}$ & $\mathrm{c}$ & $\mathrm{c}$ \\
& shape & $\mathrm{flu}$ & $\mathrm{flu}$ & $\mathrm{flu}$ \\
\hline
\end{tabular}

flu: Fluidity, sp: Specific; o: Opaque, c: Clear

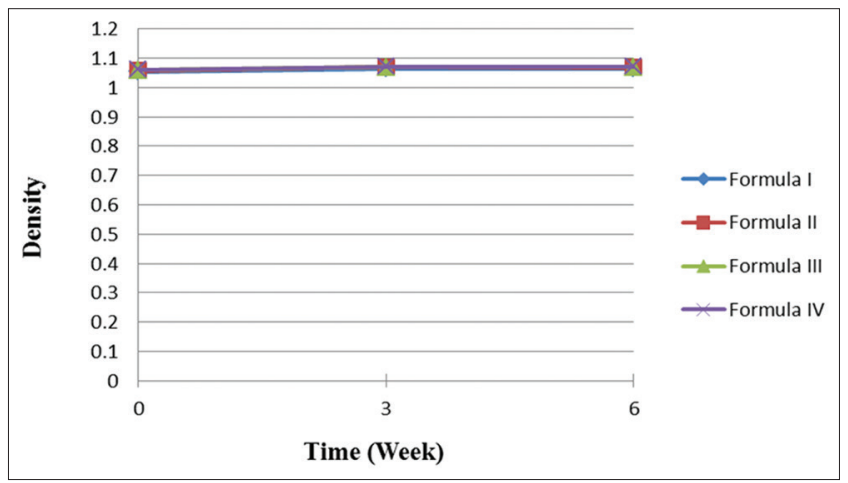

Fig. 1: Graph of density measurement

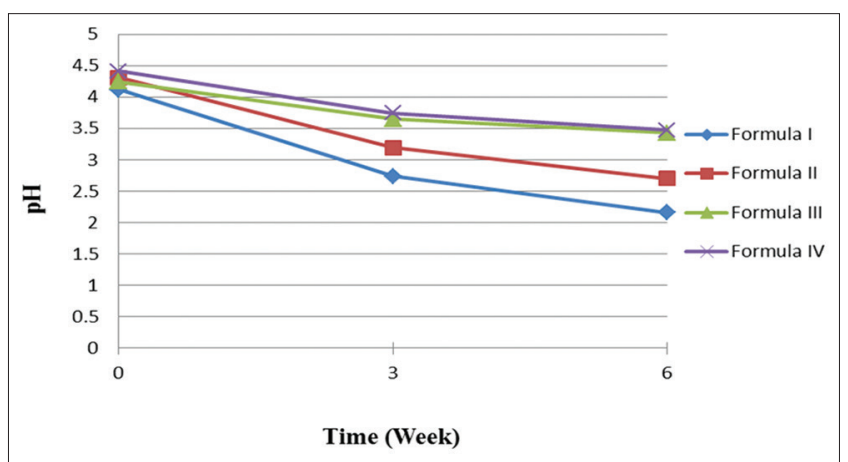

Fig. 2: Differences in $\mathrm{pH}$ of four formulas within 6 weeks storage

decrease in the surface tension [6]. From the graph, we can see that the formula F3 tends to be more stable than the other formulas. 


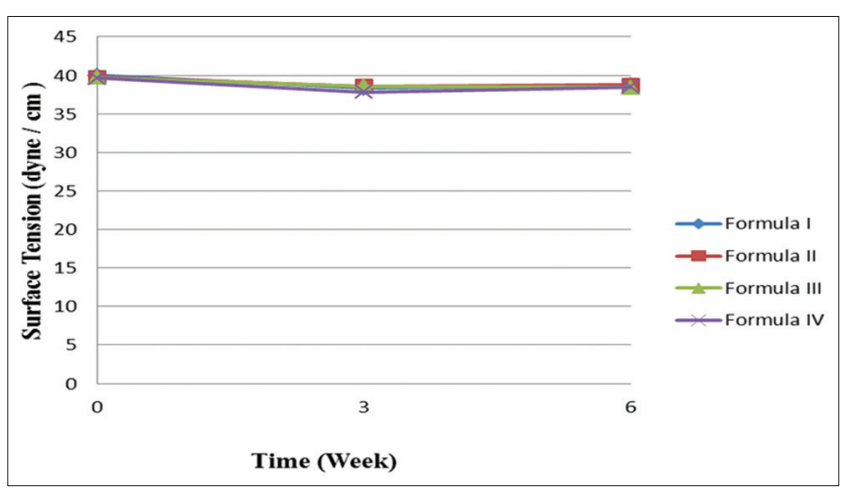

Fig. 3: Graph of surface tension measurement

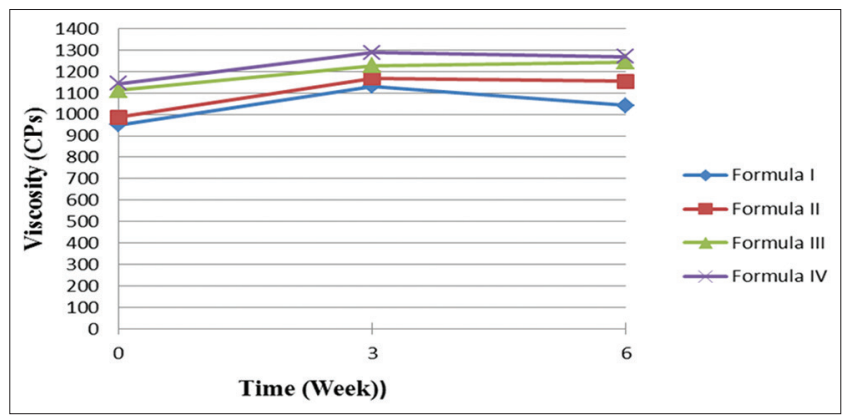

Fig. 4: Graph of viscosity measurements

\section{Viscosity measurements}

The viscosity measurement results showed that with increasing surfactant concentration, the viscosity of the microemulsion also increases (Fig. 4). Theoretically, with higher emulsifier concentration, the viscosity also increases [6]. From the graph, it can be seen that the formula F3 tends to be more stable than the others.

\section{Phase separation}

Results of the centrifugation test conducted at a speed of $3750 \mathrm{rpm}$ for 5 hrs are listed in Table 3. From these observations, only the F1 formula exhibits separation with the formation of creaming. For F2, F3, and F4, no occurrence of separation was observed, which indicates that these are fairly stable microemulsions. Centrifugation at $3750 \mathrm{rpm}$ for $5 \mathrm{hrs}$ is equivalent to the effect of gravity for about 1 year [3]. Results of the freeze-thaw cycles conducted for 6 cycles are listed in Table 4.

At a temperature of $45^{\circ} \mathrm{C}$, the $\mathrm{F} 1$ formula underwent phase separation in the $1^{\text {st }}$ cycle, as seen with the formation of creaming at the top of the microemulsion. For formula F2, phase separation occurs in the $3^{\text {rd }}$ cycle, as also seen with the formation of creaming at the top of the microemulsion. For formulas F3 and F4, there is no visible occurrence of phase separation. This suggests that these formulas are stable to changes in extreme temperatures.

\section{Particle size measurement}

The particle size of the F3 microemulsion was measured, which is considered the most stable as seen from the evaluation results of organoleptic, pH, viscosity, surface tension, freeze-thaw, and centrifugation tests. The results of the particle size measurement are presented in Table 5.

The results show that the F3 formula particles had an average diameter of $49.46 \pm 6.91 \mathrm{~nm}$. This is proved that the F3 aspirin microemulsion met
Table 3: Centrifugation of aspirin microemulsions

\begin{tabular}{ll}
\hline Formula & Speed $(3750 \mathrm{rpm})$ \\
\hline F1 & + \\
F2 & - \\
F3 & - \\
F4 & - \\
\hline
\end{tabular}

$(+)$ : The separation occurs, (-): The separation does not occur

Table 4: Results of freeze-thaw cycles

\begin{tabular}{|c|c|c|c|c|c|c|c|c|c|c|c|c|c|}
\hline \multirow[t]{2}{*}{ Cycles } & \multirow[t]{2}{*}{ Temperature } & \multicolumn{3}{|c|}{ F1 } & \multicolumn{3}{|c|}{ F2 } & \multicolumn{3}{|c|}{ F3 } & \multicolumn{3}{|c|}{ F4 } \\
\hline & & $\mathbf{A}$ & B & C & $\mathbf{A}$ & B & C & $\mathbf{A}$ & B & C & $\mathbf{A}$ & B & C \\
\hline \multirow[t]{2}{*}{1} & $4^{\circ} \mathrm{C}$ & - & - & - & - & - & - & - & - & - & - & - & - \\
\hline & $45^{\circ} \mathrm{C}$ & + & + & + & - & - & - & - & - & - & - & - & - \\
\hline \multirow[t]{2}{*}{2} & $4^{\circ} \mathrm{C}$ & + & + & + & - & - & - & - & - & - & - & - & - \\
\hline & $45^{\circ} \mathrm{C}$ & + & + & + & + & - & - & - & - & - & - & - & - \\
\hline \multirow[t]{2}{*}{3} & $4^{\circ} \mathrm{C}$ & + & + & + & + & - & - & - & - & - & - & - & - \\
\hline & $45^{\circ} \mathrm{C}$ & + & + & + & + & + & + & - & - & - & - & - & - \\
\hline \multirow[t]{2}{*}{4} & $4^{\circ} \mathrm{C}$ & + & + & + & + & + & + & - & - & - & - & - & - \\
\hline & $45^{\circ} \mathrm{C}$ & + & + & + & + & + & + & - & - & - & - & - & - \\
\hline \multirow[t]{2}{*}{5} & $4^{\circ} \mathrm{C}$ & + & + & + & + & + & + & - & - & - & - & - & - \\
\hline & $45^{\circ} \mathrm{C}$ & + & + & + & + & + & + & - & - & - & - & - & - \\
\hline \multirow[t]{2}{*}{6} & $4^{\circ} \mathrm{C}$ & + & + & + & + & + & + & - & - & - & - & - & - \\
\hline & $45^{\circ} \mathrm{C}$ & + & + & + & + & + & + & - & - & - & - & - & - \\
\hline
\end{tabular}

$(+)$ : The separation occurs, (-): The separation does not occur

Table 5: Particle size measurement of aspirin microemulsion

\begin{tabular}{lll}
\hline Formula & Particle size diameter $(\mathbf{n m})$ & PI \\
\hline F3 & 42.8 & 11.967 \\
& 56.6 & 14.995 \\
Average & 49.0 & 18.309 \\
\hline
\end{tabular}

PI: Polydispersity index

the particle size requirements. However, more research is needed on the $\mathrm{pH}$ of the aspirin microemulsions, to obtain the ideal $\mathrm{pH}$ preparations. It is also necessary to test the physical and chemical stability of the aspirin microemulsion.

\section{CONCLUSION}

The results of this research indicated that the optimal concentration of Tween 80 as a surfactant and propylene glycol as a cosurfactant (2:1) is $60 \%$. This microemulsion formula exhibited a pH value of $3.74 \pm 0.30$ $\mathrm{pH}$, viscosity of $1198.76 \pm 56.02 \mathrm{cps}$, BJ of $1.0669 \pm 0.005 \mathrm{~g} / \mathrm{mL}$, surface tension of $38.77 \pm 0.43$ dyne $/ \mathrm{cm}$, and particle size of $49.46 \pm 6.91 \mathrm{~nm}$.

\section{REFERENCES}

1. Ammar HO, Ghorab M, El-Nahhas SA, Kamel R. Design of a transdermal delivery system for aspirin an antithrombotic drug. Int J Pharm 2006;327(1-2):81-8.

2. Kogan A, Garti N. Microemulsions as transdermal drug delivery vehicles. Adv Colloid Interface Sci 2006;123-126:369-85.

3. Khar RK, Vyas SP, Ahmad FJ, Jain GK. Lachman/Lieberman's the Theory and Practice of Industrial Pharmacy. $4^{\text {th }}$ ed. India: CBS Publishers and Distribution; 2013.

4. Department of Health. Farmakope Indonesia IV. Jakarta: Department of Health; 1995.

5. Noerono S. Buku Pelajaran Teknologi Farmasi. Yogyakarta: Universitas Gajah Mada Press; 1994

6. Rowe RC, Paul JS, Quinn ME. Handbook of Pharmaceutical Excipient. $6^{\text {th }}$ ed. Washington, DC, Grayslake: Pharmaceutical Press and American Pharmacists Association; 2009. 